\title{
INTERNET BASED SERVICE DEVELOPMENT
}

\author{
Olli Martikainen, Jouni Karvo \\ Helsinki University of Technology, \\ Otakaari I, FIN-02150 Espoo, FINLAND, \\ Tel. +35894512174, Telefax +35894515014 , \\ E-mail \{Olli.Martikainen,Jouni.Karvo\}@hut.fi
}

\begin{abstract}
The development of telecommunications services is affected by the changes in telecommunications market and in the service provisioning technologies. The market changes follow partly from the regulatory changes and the privatisation of the teleoperator industry and partly from the growing new service providers in mobile and Internet areas. This paper suggests that the current service creation architecture used by incumbent telecom operators may loose its significance in the future. Instead, new service architectures based on Internet and mobile service provisioning models will enter.

We present forecasts on Internet access and service market and evaluate the TCP/IP based traffic in future networks. The growth of Internet based services suggests a major change in future telecommunications service provisioning technologies. Furthermore, we present possible service platforms and service management environments available in future telecom service provisioning and conclude some major technology discontinuities in the service development.
\end{abstract}

\section{INTRODUCTION}

Telecommunications growth in Europe will in the next few years concentrate in the area of mobile- and datatraffic. The turnover of services is depicted in Figure 1 (see [1] and [3]). It can be concluded from market research that the IP traffic already present in the current telecommunications networks will continue its increase. The amount of Internet traffic will outweight the amount of traditional telephone traffic, and new services and

The original version of this chapter was revised: The copyright line was incorrect. This has been corrected. The Erratum to this chapter is available at DOI: 10.1007/978-0-387-35581-8_35 
service architectures will evol\%e. The transition from the existing telecommunications services to Internet based ones will change the service infrastructure as well as service creation and management structures.

In Section 2 we describe how traffic volumes are expected to grow in the near future. Section 3 describes the service provisioning and management architectures, and the conclusions will be drawn in Section 4.

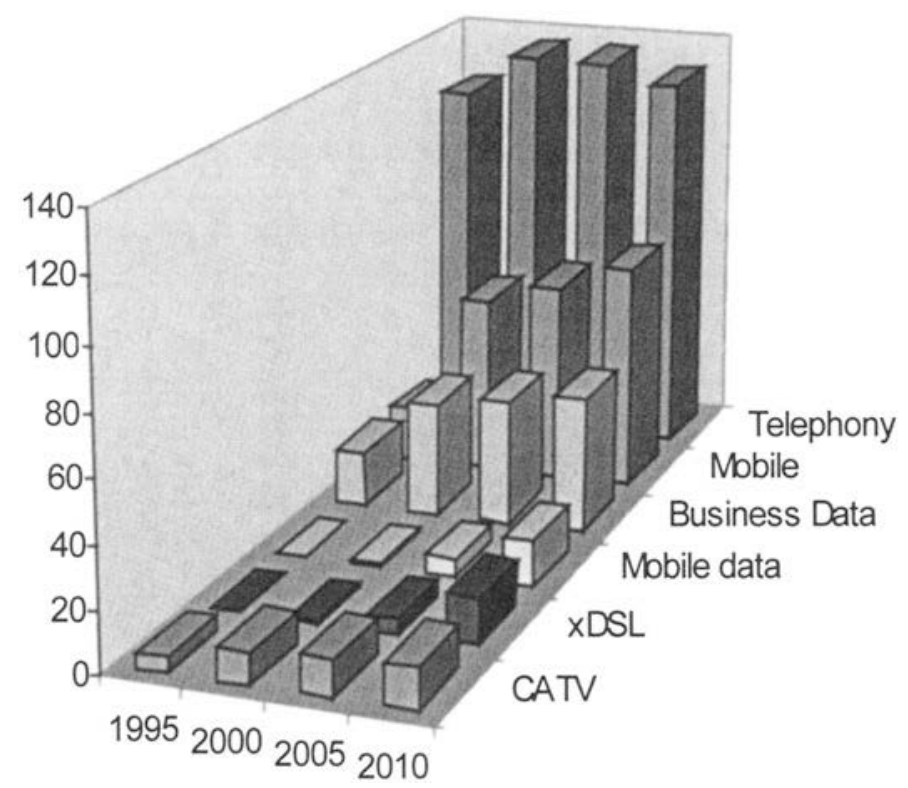

Figure 1. Telecom service turnover in Europe (Billion USD)

\section{SERVICES}

The incumbent teleoperators and their networks have been built on ISDN and B-ISDN switching where services are based on mobile, voice and IN technologies. The basic assumption has been that the peripherals are not intelligent, and all intelligence is located in network nodes. The Internet is based on the assumption on intelligent peripherals and less-intelligent network routers. The Internet growth, boosted by the invention of WorldWide Web in the early 90 's, is expected to form the majority of traffic in the future telecommunications networks.

As estimated from the market studies of EITO [1] and OVUM [3] the expected Internet capable telecommunications terminal volumes $\boldsymbol{n}_{\boldsymbol{i}}$ in 
Europe are shown in Figure 2. In the figure NB and GPRS (Global Packet Radio System) mean narrowband fixed and mobile data, and xDSL and UMTS (Universal Mobile Telecommunications System) broadband fixed and mobile data, respectively. PDA (Personal Digital Assistant) can be fixed or mobile. The expected amount of traffic generated by the terminals is yielded by the weighted sum of the expected traffic and service time per day and terminal. Let $\boldsymbol{d}_{i}$ denote the traffic generated by a terminal of type $i$, $\boldsymbol{t}_{\boldsymbol{i}}$ the expected service time per day of type $i$ terminal and $\boldsymbol{n}_{\boldsymbol{i}}$ the expected number of terminals of type $i$. Now, the total amount of traffic $L$ in the network is given by the sum over all terminal types

$$
L=\sum_{i} d_{i} \boldsymbol{t}_{\boldsymbol{i}} \boldsymbol{n}_{\boldsymbol{i}} .
$$

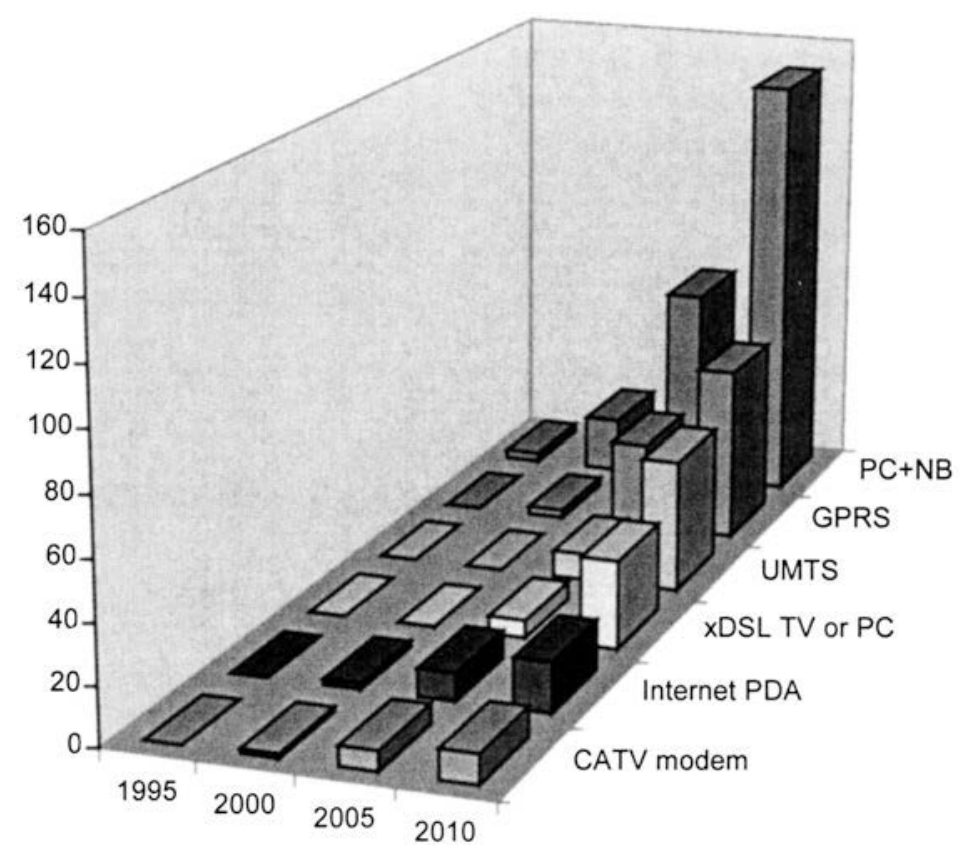

Figure 2. Internet terminals in Europe (million)

We divide services into two classes: Class 1 services could use the traditional circuit switched network with its service structure. These services include telephone, mobile phone and ISDN services. Class 2 services need seamless integration to the Internet world, namely the TCP/IP protocol suite and its service model. Typical class 2 services include electronic commerce, audiovisual content distribution and electronic 
publishing. Class 2 service turnovers in Europe are estimated in Figure 3 by us using data from [1], [2] and [3].

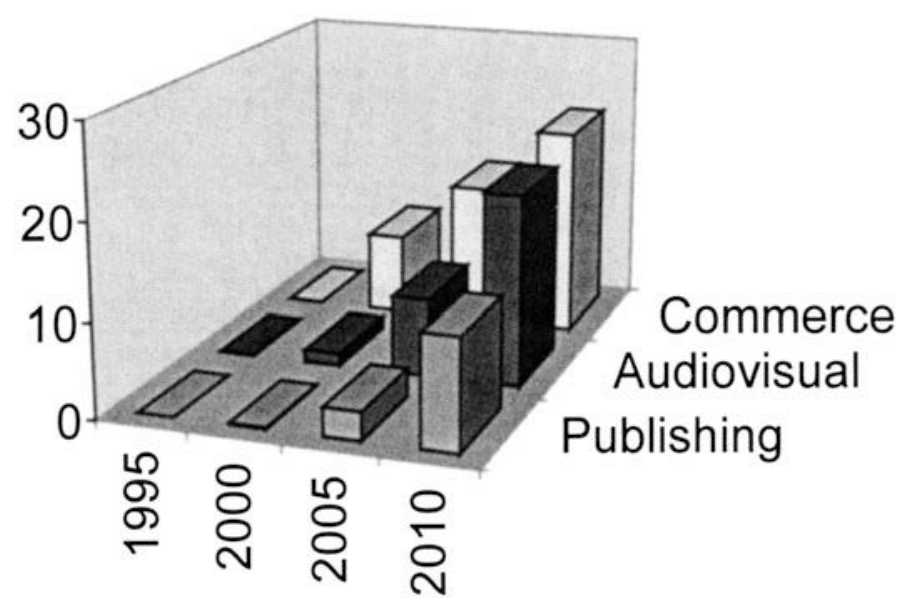

Figure 3. Turnover of TCP/IP based services in Europe (Billion USD)

Class 2 services will be based on ISDN, GPRS, xDSL, UMTS and interactive CATV connections with TCP/IP based services and Web based radio and TV programs. The expected parameters used in our calculation for each terminal type are the following:

\section{Class 1:}

- telephone and ISDN

$$
\begin{array}{ll}
\text { - telephone and ISDN } & \boldsymbol{d}_{\boldsymbol{i}}=64 \mathrm{kbps}, \boldsymbol{t}_{i}=10 \mathrm{~min} / \text { day } \\
\text { - mobile phone and GPRS } & \boldsymbol{d}_{\boldsymbol{i}}=64 \mathrm{kbps}, \boldsymbol{t}_{\boldsymbol{i}}=3 \mathrm{~min} / \text { day }
\end{array}
$$

\section{Class 2:}

- Web over ISDN $\quad d_{i}=64 \mathrm{kbps}, t_{i}=30 \mathrm{~min} /$ day

- GPRS and Internet PDA $\boldsymbol{d}_{i}=64 \mathrm{kbps}, \boldsymbol{t}_{\boldsymbol{i}}=15 \mathrm{~min} / \mathrm{day}$

- xDSL $\quad \boldsymbol{d}_{\boldsymbol{i}}=2 \mathrm{Mbps}, \quad \boldsymbol{t}_{\boldsymbol{i}}=30 \mathrm{~min} /$ day

- UMTS $\quad \boldsymbol{d}_{\boldsymbol{i}}=0.5 \mathrm{Mbps}, \boldsymbol{t}_{\boldsymbol{i}}=15 \mathrm{~min} /$ day

- interact. CATV modem $\boldsymbol{d}_{\boldsymbol{i}}=2 \mathrm{Mbps}, \quad \boldsymbol{t}_{\boldsymbol{i}}=30 \mathrm{~min} /$ day

For Class 1 we expect 243 million telephone and 111 million mobile connections in Europe in year 2000 [1]. Figure 4 shows the total expected amount of traffic $L$ calculated separately for both classes of services. In the figure it can be seen that Internet type traffic will dominate after four years time. Since IP traffic dominates, service platforms and management should be developed based on Internet and Web models. In what follows we shall 
compare traditional telecom service architecture with Internet and Web based service architectures.

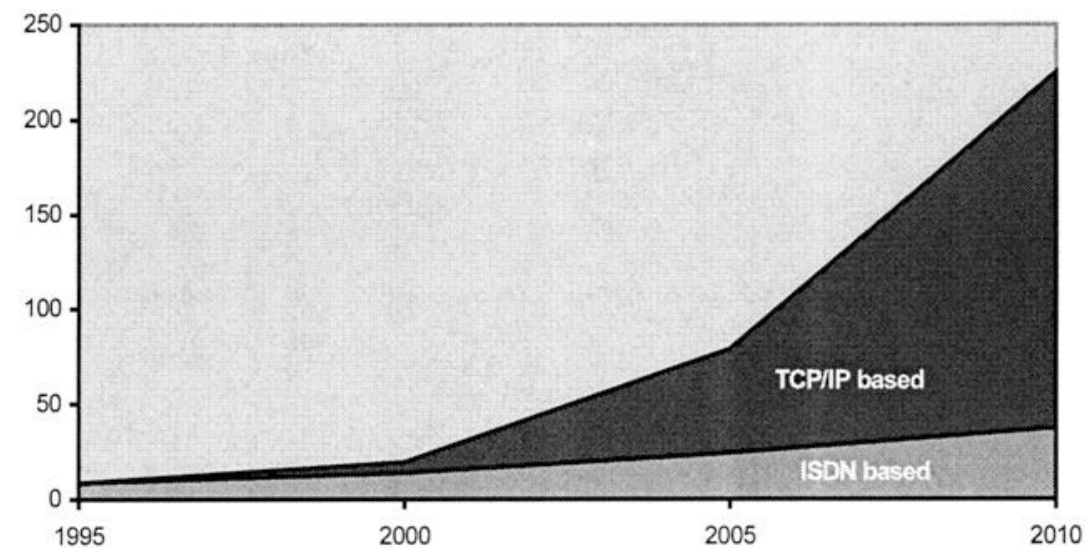

Figure 4. ISDN based and TCP/IP based traffic in Europe (Petabit/day)

\section{SERVICE ARCHITECTURES}

The incumbent teleoperator services are based on digital switches and service logic software developed for them. This is a centralized service model (Figure 5).

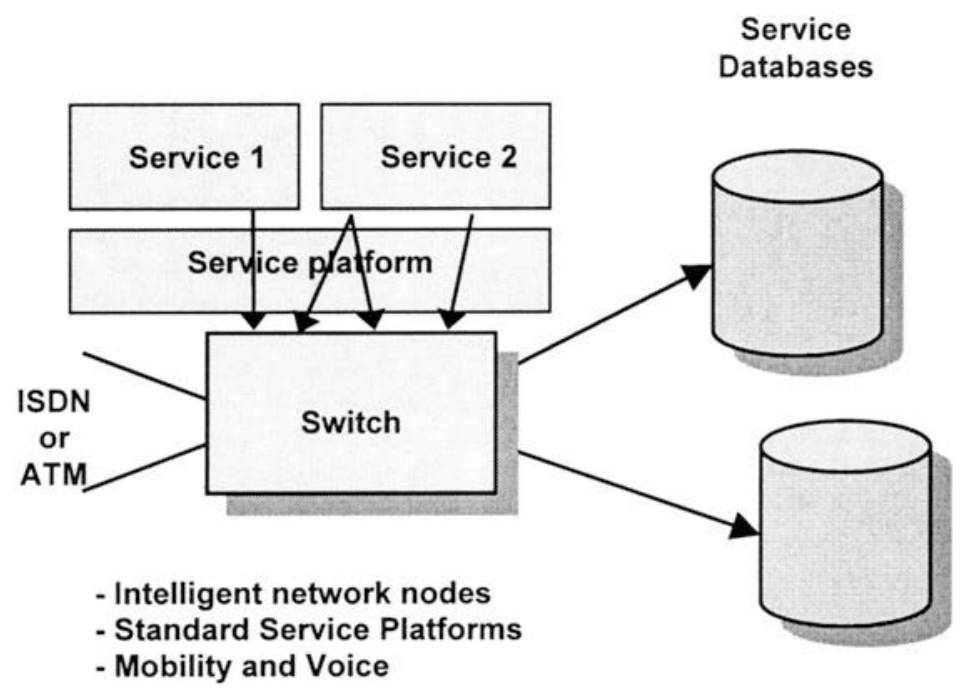

Figure 5. Traditional service model 
Internet services are based on routers and the client-server model, where services are disributed in Web servers and accessible using the corresponding Uniform Resource Locators (URL) (Figure 6).

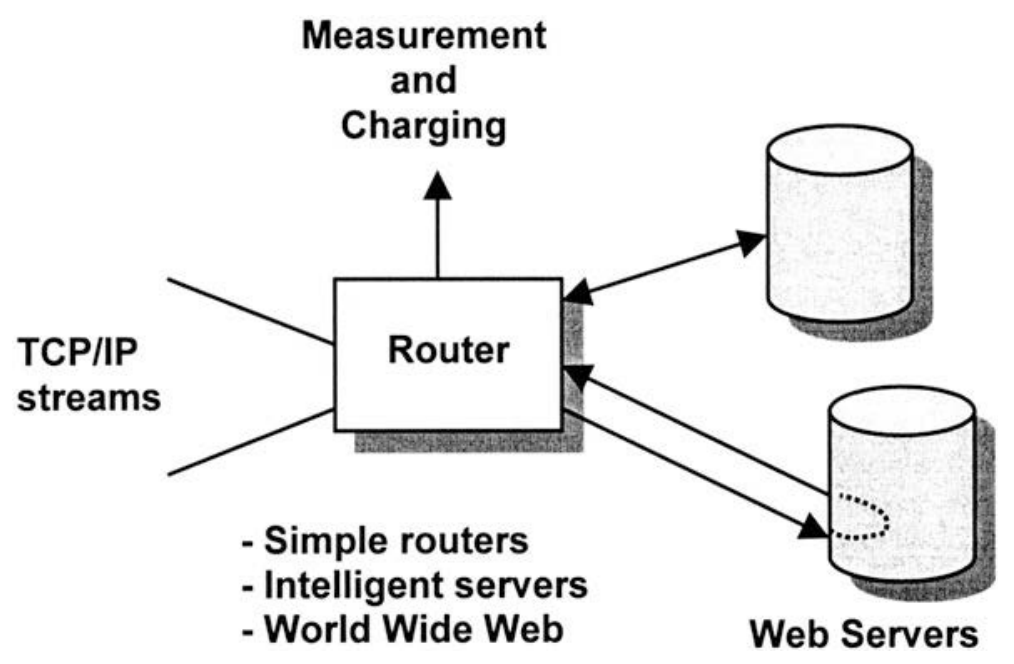

Figure 1. Internet and Web service model

Service management is based on service creation, parametrization and distribution in the network, customer identification and authentication, charging and customer billing, and necessary security features.

Incumbent teleoperators have customer databases (CDB) for customer identification and billing databases (BDB) for billing information. Customer authentication and billing is based on subscriber number (A-id) and security on closed signalling system (Figure 7). Service software is loaded in digital switches (DX) as centralized services, such as GSM and IN services. It is typical for incumbent teleoperators that the cost of the service management environment may be higher than the cost of service software and platforms. 


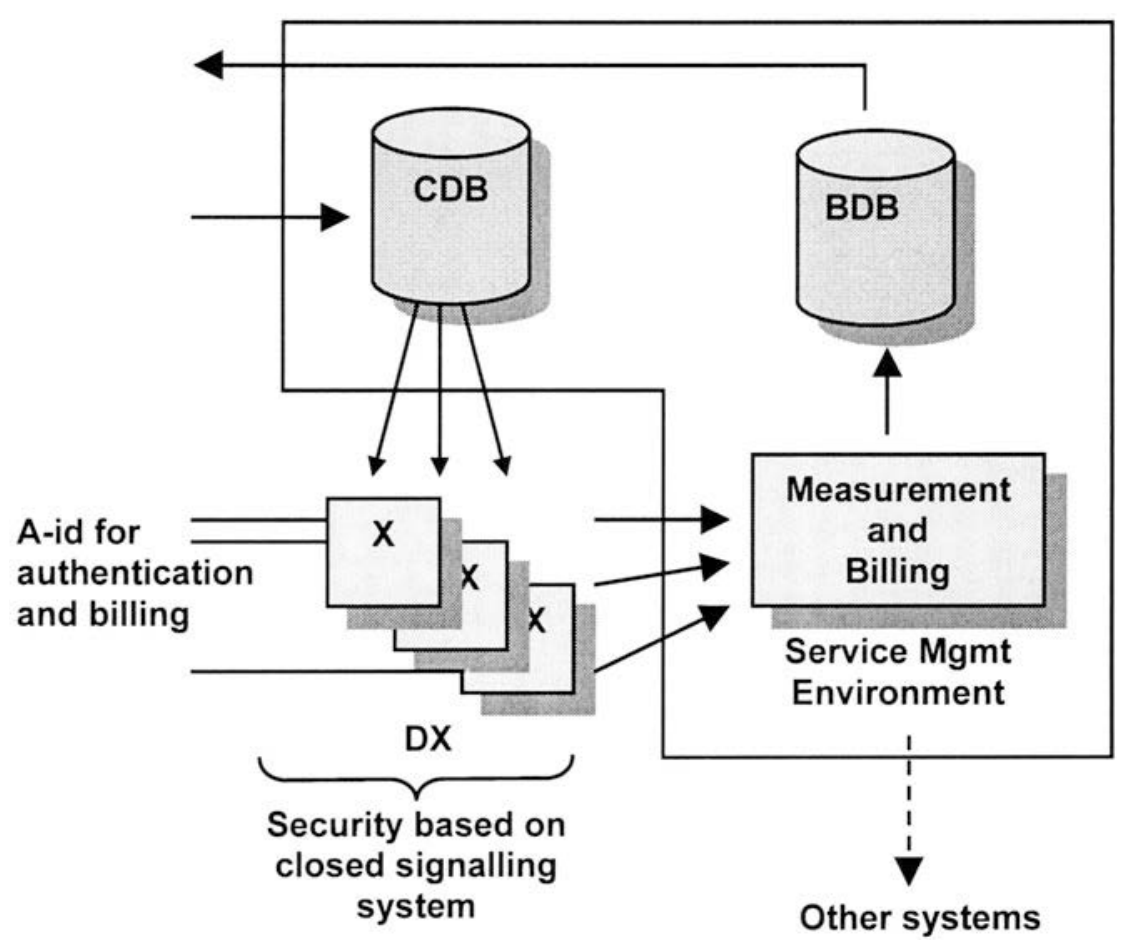

Figure 7. Traditional Service Management

Service management in Internet differs strongly from traditional service management. Users are not necessarily tied to any subscriber number so that user identification and authentication must be built in servers using specific applications. Service software is located in servers which are not usually owned by the teleoperators. Hence also the charging and customer billing must be built as separate applications. Moreover, network signalling and control data is carried on the same connections as the user and service specific data. This means that separate security functions must be built to support confidentiality in the network. As a result, the Internet service management relies on separate applications specified for the service management functions, which create a "service management layer" around routers (R) and basic TCP/IP connections (Figure 8). 


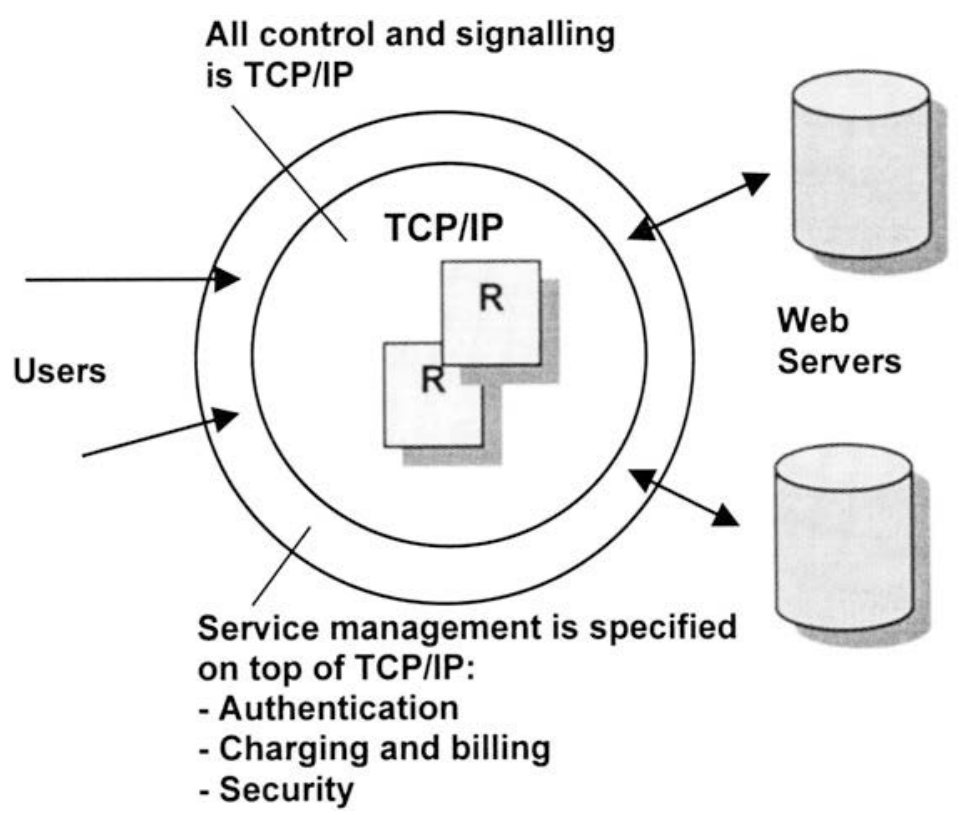

Figure 8. Internet Service Management

\section{CONCLUSION}

The service management environment takes care of service creation and distribution in the network and of customer and service related data. The difference of Internet based services compared to incumbent teleoperator services is not only in the service application structure and service platforms but also in service management environments.

In fact, differences in service management between traditional and Internet environments are more profound than differences in basic service applications. As a result we conclude that the new structure for service management needed in the Internet environment will be a key success factor for large scale TCP/IP based service provisioning in the near future.

\section{REFERENCES}

[1] European Information Technology Observatory 98 (EITO) - European Economic Interest Grouping, http://www.fvit-eurobit.de/eito

[2] IDATE 1998, http://www.idate.fr

[3] OVUM Forecasts: Key Telecom Markets, 1998, http://www.ovum.com 